\title{
EL CONSTRUCTIVISMO EN EL AULA
}

Coll, César; Martín, Elena; Mauri, Teresa; Miras, Mariana; Onrubia, Javier; Solé Gallart, Isabel y Zabala, Antoni. Editorial Graó, Barcelona, 2005, 183 p.

\section{DATOS SOBRE LOS AUTORES}

Cesar Coll: Doctor en Psicología de la Educación (Universidad de Barcelona). Elena Martín: Doctora en Psicología y profesora titular del Departamento de Psicología Evolutiva y de la Educación (Universidad Autónoma de Madrid). Teresa Mauri: Doctora en Psicología y catedrática de la Escuela Universitaria de Formación del Profesorado (Universidad de Barcelona).

Mariana Miras: Doctora en Psicología y profesora titular de Psicología de la Educación del Departamento Psicología Evolutiva y de la Educación (Universidad de Barcelona).

Javier Onrubia: Doctor en Psicología y profesor del Departamento de Psicología Evolutiva y de la Educación (Universidad de Barcelona).

Isabel Solé Gallart: Doctora en Psicología y profesora de Psicología de la Educación del Departamento de Psicología Evolutiva y de la Educación (Universidad de Barcelona).

Antoni Zabala: Licenciado en Filosofía y Ciencias de la Educación, director de la revista Aula de Innovación Educativa. 


\section{CONTENIDO}

Son siete capítulos y cada uno termina con su respectiva bibliografía.

1. Los profesores y la concepción constructivista/Isabel Solé y César Coll.

Postulan que la teoría educativa debe integrar la dimensión social de la enseñanza (p. 10). La concepción constructivista del aprendizaje y de la enseñanza acerca a la cultura y, por tanto, incluye las relaciones (p. 15). Aprender no es copiar o reproducir la realidad. En el constructivismo aprender es elaborar una representación personal sobre un objeto de la realidad, para esto, primero hay que aprehenderlo pero desde los intereses y conocimientos previos (p. 16). Aprendizaje significativo es construir un significado propio y personal para un objeto de conocimiento que existe ( $\mathrm{p}$. 17). El propósito es construir significados adecuados en torno a los contenidos del currículo (p. 19). El constructivismo ofrece al profesor el marco para analizar y fundamentar las decisiones de planificar o comparar materiales o elegir evaluaciones, o trabajar en equipo y adoptar acuerdos (p. 20).

2. Disponibilidad para el aprendizaje y sentido del aprendizaje/Isabel Solé.

El trabajo gira en torno al interés como inicio del aprendizaje (p. 27 y 43).

3. Un punto de partida para el aprendizaje de nuevos contenidos. Los conocimientos previos / Mariana Miras.

Inicia asegurando que si los profesores pudieran plantear deseos, uno de ellos sería tener la mente en blanco de los alumnos para escribir en ella lo que deben aprender. Si esto no fuera posible habría que borrar lo que hay (p. 47). Se tienen conocimientos parciales de la realidad, no un conocimiento global (p. 52).

4. ¿Qué hace que el alumno y la alumna aprendan los contenidos escolares? La naturaleza activa y constructiva del conocimiento/ Teresa Mauri.

Rechaza el aprendizaje como copia o réplica interna de la información externa. En este caso el problema será elegir lo que se deba copiar (p. 69). La construcción del conocimiento se relaciona con la cultura (p. 75). La 
educación ha de promover la conciencia y la voluntad del alumno (p. 77); «[...] en la mente no se encuentra la cosa "real", sino la idea o representación que hemos elaborado de ella poniendo en juego lo que ya conocíamos» (p. 78). Señala pautas para aprender actitudes (p. 96).

5. Enseñar: crear zonas de desarrollo próximo e intervenir en ellas/Javier Onrubia.

En enfoque se centra en la enseñanza como ayuda para incrementar la capacidad de comprensión y actuación autónoma (p. 104). Adopta de Vygotsky el concepto de ZDP como la distancia entre el nivel de resolución de una tarea que una persona puede alcanzar actuando independientemente, y el nivel que puede lograr con la ayuda de un compañero más competente y experto (p. 104).

\section{Los enfoque didácticos/ Antoni Zabala.}

La idea es revisar cómo elegir el mejor método de enseñanza y la respuesta la proporciona el que promueve la mayor actividad del educando (p. 125). Para aprender a aprender presenta un cuadro (p. 135).

7. La evaluación del aprendizaje en el currículo escolar: Una perspectiva constructivista/César Coll y Elena Martín.

Muestran dos cuadros para trabajar los puntos por evaluar (p. 168 y 180). Los resultados de la evaluación dependen de los significados construidos y del sentido que se atribuye a las actividades previas de la enseñanza y el aprendizaje, y de la propia evaluación (p. 173). La evaluación, más que de la enseñanza y del aprendizaje, debe ser de los procesos (p. 177).

\section{VALORACIÓN CRÍTICA}

Es muy adoptable la dimensión social y la vinculación con la cultura promovida por la educación constructivista, el interés por la conciencia y la voluntad de los educandos, la inquietud por alcanzar un eficaz aprendizaje y la evaluación de procedimientos.

Sin embargo, es evidente el origen del constructivismo a partir de la postura inmanentista pues la construcción intelectual no se apoya en la potencia del ser humano y, fundamentalmente, se desconoce el modo de 
asimilar las esencias en la primera operación de la mente o simple aprehensión, esto lleva a la poca confianza en los conocimientos previos y al desconocimiento de la posesión de la verdad ontológica. Para ellos, los conceptos no son universales y, por eso, los confunden con juicios y razonamientos.

En el constructivismo no se puede disfrutar lo siguiente: «Pensar es imaginar por dentro lo que la naturaleza representa por fuera, copiar en sí misma la escritura de la naturaleza. Pensar es ver, y su órgano es el ojo interior, negado a los ineptos. Así pues, la lógica no es argumentar, sino un contemplar, una intuición intelectual no de las ideas, que son de Dios, sustancia fuera del conocimiento, sino de las sombras o reflexiones de las ideas en los sentidos y en la razón» ${ }^{1}$.

Ana Teresa López de Llergo Villagómez

Francesco De Sanctus, «Storia Della Letteratura Italiana», cap. XIX, en N. Gallo, La nueva ciencia, vol. II, Einaudi, 1958, p. 750. 